\title{
How admissions to various medical specialty divisions determines the outcome of patients with hepatocellular carcinoma: results from a retrospective study in a large hospital of northwest China
}

This article was published in the following Dove Press journal:

Therapeutics and Clinical Risk Management

18 April 2017

Number of times this article has been viewed

\author{
Qianqian Zhu' \\ $\mathrm{Na} \mathrm{Li}$ \\ Fang $\mathrm{Li}^{\prime}$ \\ Zhihua Zhou' \\ Jiao Sang' \\ Xiaoyan Zeng ${ }^{2}$ \\ Qunying Han' \\ Yi Lv ${ }^{3,4}$ \\ Wenxuan Zhao' \\ Zhengwen Liu' \\ 'Department of Infectious Diseases, \\ ${ }^{2}$ Department of Laboratory Medicine, \\ ${ }^{3}$ Department of Hepatobiliary \\ Surgery, The First Affiliated Hospital \\ of Xi'an Jiaotong University, \\ ${ }^{4}$ Institute of Advanced Surgical \\ Technology and Engineering, Xi'an \\ Jiaotong University, Xi'an, Shaanxi, \\ People's Republic of China
}

Background and objective: The treatment of hepatocellular carcinoma (HCC) involves multidisciplinary clinical divisions and patients may be admitted to clinical divisions of different disciplinary nature. Few studies have assessed the potential effect of hospital admissions into different divisions on patient treatment options and survival. This study aimed to analyze this potential effect.

Methods: We analyzed data of HCC patients between 2002 and 2011 in a large hospital of northwest China and compared the treatment options and patient outcomes following initial admission into two major clinical disciplinary divisions: internal medicine and surgical. Barcelona Clinic Liver Cancer criteria were used for staging.

Results: The study included 2,045 patients. Analysis showed that more patients initially admitted to surgical divisions received curative treatments (resection, transplantation, and local ablation) than those admitted to internal medicine divisions; while more patients initially hospitalized to internal medicine divisions chose supportive care than those admitted to surgical divisions. Stages 0 , A, and B patients initially admitted to surgical divisions had higher survival rates compared with those initially admitted to internal medicine divisions $(P=0.036,0.057$ and 0.001 , respectively). Survival rates of patients who were in stages $\mathrm{C}$ and $\mathrm{D}$ showed no differences. The survival differences between patients initially admitted to internal medicine and surgical divisions vanished after adjusting for treatment distribution.

Conclusion: This study showed that the initial hospitalization divisions may affect the outcome of HCC patients because of different treatment options, suggesting that enforcing multidisciplinary collaboration to optimize the treatment of HCC patients at various stages may improve patient survival.

Keywords: hepatocellular carcinoma, treatment option, outcome, multidisciplinary cooperation

\section{Introduction}

As one of the most common cancers, hepatocellular carcinoma (HCC) is the third most prevalent cause of cancer-related death. ${ }^{1} \mathrm{HCC}$ is a complex disease. Its development is associated with various etiologies including hepatitis $\mathrm{B}$ virus (HBV), hepatitis $\mathrm{C}$ virus (HCV), high alcohol intake, aflatoxin B1, and metabolic syndrome. ${ }^{2}$ Furthermore, mixed etiologies presented in some patients may act in a synergistic or an additive mechanism in the development of HCC. The course of HCC development is a multistage process
Correspondence: Zhengwen Liu Department of Infectious Diseases, The First Affiliated Hospital of Xi'an Jiaotong University, 277 West Yanta Road, Xi'an, Shaanxi 7I006I,

People's Republic of China

Tel +86 I89 9|23 233।

Email liuzhengwen@medmail.com.cn 
with different severities of underlying liver disease varying from normal liver to cirrhosis. ${ }^{3}$ Most HCCs are related to chronic hepatitis and more than $80 \%$ of them develop with underlying cirrhosis. ${ }^{4,5}$ Early diagnosis is important for allowing potentially curative treatments such as resection, liver transplantation, and radiofrequency ablation. ${ }^{6}$ Unfortunately, a high proportion of patients are diagnosed with HCC at a more advanced stage, resulting in poor prognosis. ${ }^{4,7}$ The treatment options for advanced stage HCC include resection, radiation, chemotherapy, and supportive therapy as well as sequential or combination treatment of these therapeutics. The multifactorial etiology, multistage process, complexity that underlies the course of HCC development, and the existence of multiple treatment options which depends upon the disease stage have led to a complex involvement of clinical divisions of multidiscipline nature in the management of HCC patients. In fact, many clinical divisions including infectious disease, gastroenterology, hepatobiliary surgery, general surgery, internal oncology, radiation oncology, and surgical oncology are often involved in the management of HCC. Diagnosis may be established and the patients may be admitted in any of these clinical divisions. There are multiple treatment choices, which must be tailored to each patient's need, according to tumor stage, liver function, etiology, liver status, and performance status. ${ }^{6,8}$ However, many other factors, in addition to clinical factors, may influence the decision of treatment choice. Studies show that some nonclinical factors can influence the treatment choice of HCC, especially the surgeon specialty - although the relationship between nonclinical decisions and survival remains unclear. ${ }^{9,10}$ For example, a study from the United States shows that referral patterns vary considerably and may be related to treatment choices for patients with HCC. ${ }^{10}$

In view of the complexity of HCC, cooperation of a multidisciplinary team (MDT) is needed to guarantee appropriate treatment for HCC and underlying liver disease. ${ }^{11}$ An MDT, as defined by United Kingdom Department of Health, is based on coordination and communication among specialists of different healthcare disciplines and aims to make an informed decision for cancer patients. However, the utilization of MDTs for HCC treatment is not universal and is especially scarce in Asia. ${ }^{12}$ Furthermore, many practical barriers have reduced the effectiveness of MDTs. ${ }^{13}$ Some researchers have suggested that it is important to examine the relationship between multidisciplinary care and patient survival, and other evidence to make the MDT work efficiently. ${ }^{14,15}$

In the light of the situation that $\mathrm{HCC}$ patients may be referred to, and be admitted to, different clinical divisions, and the possibility that the nature of clinical divisions could influence the choice of treatment and the ultimate survival of patients, this retrospective study was carried out. Thus, we have examined the outcome of HCC patients admitted into either surgical or internal clinical divisions, using data from a 10-year period from a large university hospital in northwest China, where the work of the MDT is in its initial and preliminary stage.

\section{Methods}

\section{Setting and data}

This study is based on data from a previously described cohort. ${ }^{16}$ Briefly, medical records of patients with primary diagnosis of $\mathrm{HCC}$ and being admitted to various divisions between 2002 and 2011 in the First Affiliated Hospital of Xi'an Jiaotong University were retrospectively reviewed. All the patients with $\mathrm{HCC}$ were included in the primary review. Patients who were not first diagnosed and admitted for HCC in this hospital were excluded. Only the patients who were both firstly diagnosed and admitted for HCC treatment in this hospital were included in the analysis.

The stages of HCC were classified according to the Barcelona Clinic Liver Cancer (BCLC) staging system as recommended by the American Association for the Study of Liver Diseases guideline. ${ }^{6,17}$ This system classifies patients with HCC into five categories: very early (0), early (A), intermediate (B), advanced (C), and terminal (D) stages.

\section{Treatments}

The treatments were classified into liver transplantation; resection; percutaneous local ablation including percutaneous local ablation with ethanol injection or radiofrequency; transcatheter arterial chemoembolization (TACE); combination treatment with at least two of the treatments: resection, percutaneous local ablation, and TACE; supportive and symptomatic treatment; and other treatments including systemic chemotherapy, sorafenib, traditional Chinese medicine, or conformal radiation therapy according to the actual existing treatments in the present retrospective study. For the further analysis, liver resection, liver transplantation, percutaneous local ablation, and the combination treatment were included as potentially curative treatments. TACE and sorafenib were considered as palliative treatment. Supportive and symptomatic treatment and other treatments including traditional Chinese medicine were regarded as supportive care.

\section{Etiology of HCC}

The etiology of liver disease was classified as HBV, HCV, $\mathrm{HBV}$ and $\mathrm{HCV}$ coinfection and others including non-HBV or HCV virus infection, alcohol, metabolic syndrome, and unavailable reason from the medical records. 


\section{Classification of clinical divisions}

The clinical divisions involved in the admission for HCC patients in the hospital included infectious diseases, gastroenterology, internal oncology, radiation oncology, surgical oncology, hepatobiliary surgery, general surgery, and vascular surgery. The initial admission divisions according to the disciplines and specialty were divided into two major discipline natures: 1) divisions of an internal medicine nature, including infectious diseases, gastroenterology, radiation oncology, internal oncology, and traditional Chinese medicine; and 2) divisions of surgical nature, including hepatobiliary surgery, general surgery, surgical oncology, and vascular surgery. After initial hospitalization, the patients usually received a treatment choice according to the disease stage, etiology, liver status, and performance status ${ }^{6,8}$ after consultation from physicians of different specialties from different divisions of disciplines and may be transferred to surgical divisions for those who were initially admitted to divisions of internal medicine if resection, transplantation, or other surgical procedure were recommended. On the contrary, patients who were initially admitted to surgical divisions may or may not have been transferred to the divisions of internal medicine even if a surgical procedure was not recommended after consultation with physicians from divisions of different specialties and disciplines. In any case, the agreement of patients and their family members was obtained.

\section{Survival and statistical analysis}

Survival was the measure used in assessing the difference between divisions of internal medicine and surgical natures. Survival time was defined as the interval between diagnosis as HCC and death associated with HCC at the end of 2013. Lost to follow-up included those who died from other diseases, and cases surviving at the end of 2013 were defined as censored data. Survival curves were analyzed by the Kaplan-Meier method, and the log-rank test was used to compare the difference between groups. Cox analysis with enter method was also used. Life-table method was used to calculate the 1-, 3-, and 5-year survival rates. Quantitative data were expressed as mean \pm standard deviation (SD); qualitative data and ordinal data were expressed as absolute frequencies. Student's $t$-test was used to compare quantitative data between two groups, and Chi-squared test was used for the qualitative data and ordinal data. Statistical analyses were performed using SPSS 21.0 statistical software (SPSS, Inc., Chicago, IL, USA). A two-tailed $P$-value $<0.05$ was considered statistically significant.

\section{Ethical standard}

This study was approved by the Ethics Committee of the First Affiliated Hospital of Xi'an Jiaotong University and was carried out in compliance with the Helsinki Declaration. The requirement for informed consent was waived because of the retrospective nature of the study and using data from which the patients' identification information had been removed.

\section{Results Characteristics of patients}

In total, 2,745 patients diagnosed with HCC were reviewed. Five hundred and seventy patients who were not firstly diagnosed and treated as HCC in this hospital, 76 patients with other cancers, and 54 patients with serious comorbidities not related to $\mathrm{HCC}$ were excluded from the study. Two thousand and forty-five patients with an average of 43.6 months follow-up were eligible for inclusion and analysis. Of these 2,045 patients, 779 patients were initially admitted to internal medicine divisions and 1,266 to surgical divisions.

The gender ratio and mean age showed no significant difference between patients initially admitted to internal medicine and surgical divisions. The etiology distribution of the two groups of patients was different, with more non-HBV or $\mathrm{HCV}$ virus infection and cryptogenic etiology patients being admitted to surgical divisions $(P=0.015$, Table 1$)$. Hepatic transaminase (alanine transaminase [ALT] and aspartate transaminase [AST]) levels of patients initially hospitalized to internal medicine divisions were higher than those to surgical divisions. Patients initially hospitalized in internal medicine divisions had more Child-Pugh class B and $\mathrm{C}$ patients than those hospitalized to surgical divisions $(P<0.001$, Table 1$)$.

\section{HCC features}

Like the Child-Pugh class, patients initially hospitalized to internal medicine divisions had less BCLC stages 0 and A, and more stage $\mathrm{D}$ than those hospitalized to surgical divisions ( $P=0.005,<0.001$, and $<0.001$, respectively, Table 2 ). There were no differences between the two divisions in observed metastasis $(P=0.352$, Table 2$)$.

\section{Treatment options}

Supportive care and TACE were the most common treatment options in the whole cohort of patients $(31.9 \%$ and $31.0 \%$, respectively, Table 3 ). Treatment options were significantly different between the two divisions; more patients initially hospitalized in internal medicine divisions chose supportive care $(51.6 \%$ vs $19.7 \%, P<0.001)$ and other therapies $(8.1 \%$ vs $4.5 \%, P=0.001)$ compared with those initially hospitalized 
Table I Demographics, etiology, biochemistry, and Child-Pugh class of liver disease in the patients between internal medicine divisions and surgical divisions

\begin{tabular}{|c|c|c|c|c|}
\hline & $\begin{array}{l}\text { Total } \\
\text { n (\%) }\end{array}$ & $\begin{array}{l}\text { Internal } \\
\text { medicine } \\
\text { divisions } \\
\text { n (\%) }\end{array}$ & $\begin{array}{l}\text { Surgical } \\
\text { divisions } \\
\text { n (\%) }\end{array}$ & $P$-value \\
\hline Gender (M/F) & $\begin{array}{l}1,662 / 383 \\
(81.3 / 18.7)\end{array}$ & $\begin{array}{l}648 / 131 \\
(83.2 / 16.8)\end{array}$ & $\begin{array}{l}1,014 / 252 \\
(80.1 / 19.9)\end{array}$ & 0.082 \\
\hline Age (mean $\pm S D)$ & $52.5 \pm 12.1$ & $52.9 \pm 11.8$ & $52.3 \pm 12.3$ & 0.230 \\
\hline Etiology & $2,045(100)$ & & & 0.003 \\
\hline $\begin{array}{l}\text { HBV } \\
\mathrm{HCV} \\
\mathrm{HBV}+\mathrm{HCV}\end{array}$ & $\begin{array}{l}1,504(73.5) \\
83(4.1)\end{array}$ & $\begin{array}{l}587(75.4) \\
38(4.9)\end{array}$ & $\begin{array}{l}917(72.4) \\
45(3.6)\end{array}$ & $\begin{array}{l}0.146 \\
0.141 \\
0.445\end{array}$ \\
\hline $\begin{array}{l}\mathrm{HBV}+\mathrm{HCV} \\
\text { Others }\end{array}$ & $\begin{array}{l}17(0.8) \\
44 \mid(21.6)\end{array}$ & $\begin{array}{l}8(1.0) \\
146(18.7)\end{array}$ & $\begin{array}{l}9(0.7) \\
295(23.3)\end{array}$ & $\begin{array}{l}0.445 \\
0.015\end{array}$ \\
\hline ALT IU/L & $2,045(100)$ & & & 0.007 \\
\hline$<40$ & $783(38.3)$ & $265(34.0)$ & $518(40.9)$ & 0.002 \\
\hline $\begin{array}{l}40-200 \\
>200\end{array}$ & $\begin{array}{l}\text { I, I7I (57.3) } \\
91(4.4)\end{array}$ & $\begin{array}{l}479(61.5) \\
35(4.5)\end{array}$ & $\begin{array}{l}692(54.7) \\
56(4.4)\end{array}$ & $\begin{array}{l}0.002 \\
0.941\end{array}$ \\
\hline AST IU/L & $2,045(100)$ & & & $<0.001$ \\
\hline$<40$ & $401(19.6)$ & $94(12.1)$ & $307(24.2)$ & $<0.001$ \\
\hline $40-200$ & $1,399(68.4)$ & $540(69.3)$ & $859(67.9)$ & 0.488 \\
\hline$>200$ & $245(12.0)$ & 145 (I8.6) & $100(7.9)$ & $<0.00 \mathrm{I}$ \\
\hline Child-Pugh class & $\mathrm{I}, 843(100)$ & & & $<0.001$ \\
\hline A & $959(52.0)$ & $267(39.0)$ & $692(59.8)$ & $<0.001$ \\
\hline B & $77 \mid(4 I .8)$ & 342 (49.9) & $429(37.0)$ & $<0.001$ \\
\hline $\mathrm{C}$ & $113(6.2)$ & $76($ (II.I) & $37(3.2)$ & $<0.001$ \\
\hline $\begin{array}{l}\text { Portal vein } \\
\text { thrombosis }\end{array}$ & $\mathrm{I}, 787(100)$ & & & 0.005 \\
\hline Yes & $465(26.0)$ & 194 (29.8) & 27I (23.8) & \\
\hline No & $1,322(74.0)$ & $456(70.2)$ & 866 (76.2) & \\
\hline
\end{tabular}

Abbreviations: ALT, alanine transaminase; AST, aspartate transaminase; HBV, hepatitis $B$ virus; $\mathrm{HCV}$, hepatitis $C$ virus; $M / F$, male/female; $S D$, standard deviation.

into surgical divisions (Table 3 ). In contrast, more patients initially admitted to surgical divisions were treated by resection $(15.5 \%$ vs $1.5 \%, P<0.001)$ and percutaneous local ablation $(9.9 \%$ vs $2.3 \%, P<0.001)$ than those admitted to internal medicine divisions (Table 3 ).

Table 2 Features of hepatocellular carcinoma in the patients between internal medicine divisions and surgical divisions

\begin{tabular}{|c|c|c|c|c|}
\hline & n (\%) & $\begin{array}{l}\text { Internal } \\
\text { medicine } \\
\text { divisions } \\
\text { n (\%) }\end{array}$ & $\begin{array}{l}\text { Surgical } \\
\text { divisions } \\
\text { n (\%) }\end{array}$ & $P$-value \\
\hline AFP & I,489 (100) & & & $<0.001$ \\
\hline$<20$ & $374(25.1)$ & $107(18.6)$ & $267(29.3)$ & $<0.001$ \\
\hline $20-200$ & $26 \mid(17.5)$ & III (19.3) & $150(16.4)$ & 0.160 \\
\hline$>200$ & $854(57.4)$ & $358(62.1)$ & $496(54.3)$ & 0.003 \\
\hline $\mathrm{BCLC}$ stage & $1,773(100)$ & & & $<0.001$ \\
\hline 0 & $32(1.8)$ & $4(0.6)$ & $28(2.5)$ & 0.005 \\
\hline A & $303(17.1)$ & $79(12.3)$ & $224(19.8)$ & $<0.001$ \\
\hline B & $\mathrm{I}, 128(63.6)$ & 405 (62.9) & $723(64.0)$ & 0.628 \\
\hline C & $197(11.1)$ & $80(12.4)$ & $117(10.4)$ & 0.185 \\
\hline D & $113(6.4)$ & 76 (11.8) & $37(3.3)$ & $<0.001$ \\
\hline Metastasis & $2,045(100)$ & & & 0.352 \\
\hline Intrahepatic & II 8 (5.8) & $5 \mathrm{I}(6.5)$ & $67(5.3)$ & \\
\hline Extrahepatic & $216(10.6)$ & $76(9.8)$ & $140(11.1)$ & \\
\hline No & I,7II (83.6) & 652 (83.7) & I,059 (83.6) & \\
\hline
\end{tabular}

Abbreviations: AFP, $\alpha$-fetoprotein; BCLC, Barcelona Clinic Liver Cancer.
Table 3 Treatments of hepatocellular carcinoma between internal medicine divisions and surgical divisions

\begin{tabular}{|c|c|c|c|c|}
\hline & n (\%) & $\begin{array}{l}\text { Internal } \\
\text { medicine } \\
\text { divisions n (\%) }\end{array}$ & $\begin{array}{l}\text { Surgical } \\
\text { divisions } \\
\text { n (\%) }\end{array}$ & $P$-value \\
\hline Treatment & $2,045(100)$ & & & $<0.001$ \\
\hline Liver transplant & $26(1.3)$ & $5(0.6)$ & $21(1.7)$ & 0.046 \\
\hline Resection & $208(10.2)$ & $12(1.5)$ & $196(15.5)$ & $<0.001$ \\
\hline $\begin{array}{l}\text { Percutaneous local } \\
\text { ablation }\end{array}$ & $143(7.0)$ & $18(2.3)$ & $125(9.9)$ & $<0.001$ \\
\hline TACE & $633(31.0)$ & $244(3 \mid .3)$ & $389(30.7)$ & 0.777 \\
\hline Systemic therapy & 263 (12.9) & $35(4.5)$ & $228(18.0)$ & $<0.001$ \\
\hline Supportive care & $652(31.9)$ & $402(51.6)$ & $250(19.7)$ & $<0.001$ \\
\hline Other therapy & $120(5.8)$ & $63(8.1)$ & $57(4.5)$ & 0.001 \\
\hline
\end{tabular}

Abbreviation: TACE, transcatheter arterial chemoembolization.

Further subgroup analysis of the treatment options according to BCLC stages was performed. Because of the censored data in patients with stage 0 , the patients with stages 0 and $A$ were combined in the analysis. Patients with stages $\mathrm{C}$ and $\mathrm{D}$ were also combined. The treatment options according to disease stages between patients initially admitted to divisions of internal medicine and to surgical divisions were significantly different (all $P<0.001$, Table 4). A significantly higher proportion of patients initially admitted to surgical divisions received curative treatments compared with those admitted to internal medicine divisions for all BCLC stages analyzed ( $75.4 \%$ vs $26.5 \%, 42.3 \%$ vs $7.2 \%$, and $26.0 \%$ vs $5.8 \%$ for stages 0 and A, stage B, and stages C and $\mathrm{D}$, respectively, Table 4). In contrast, a significantly higher proportion of patients initially hospitalized to internal medicine divisions chose supportive care compared with those admitted to surgical divisions ( $45.8 \%$ vs $11.9 \%, 46.4 \%$

Table 4 Treatments of hepatocellular carcinoma according to disease stages between internal medicine divisions and surgical divisions

\begin{tabular}{|c|c|c|c|c|}
\hline & $\begin{array}{l}\text { Curative } \\
\text { treatments }\end{array}$ & $\begin{array}{l}\text { Palliative } \\
\text { treatments }\end{array}$ & $\begin{array}{l}\text { Supportive } \\
\text { care }\end{array}$ & $P$-value \\
\hline BCLC Stages 0 and $A$ & & & & $<0.001$ \\
\hline $\begin{array}{l}\text { Internal medicine } \\
\text { divisions }\end{array}$ & $22(26.5)$ & $23(27.7)$ & $38(45.8)$ & \\
\hline Surgical divisions & $190(75.4)$ & $32(12.7)$ & 30 (1 1.9$)$ & \\
\hline BCLC Stage B & & & & $<0.001$ \\
\hline $\begin{array}{l}\text { Internal medicine } \\
\text { divisions }\end{array}$ & $29(7.2)$ & I88 (46.4) & $188(46.4)$ & \\
\hline Surgical divisions & $306(42.3)$ & $286(39.6)$ & $131(18.1)$ & \\
\hline BCLC Stages $C$ and D & & & & $<0.001$ \\
\hline $\begin{array}{l}\text { Internal medicine } \\
\text { divisions }\end{array}$ & $9(5.8)$ & $5 \mathrm{I}(32.7)$ & $96(6 \mid .5)$ & \\
\hline Surgical divisions & $40(26.0)$ & $58(37.7)$ & $56(36.4)$ & \\
\hline
\end{tabular}

Note: Data are presented as $n$ (\%).

Abbreviation: BCLC, Barcelona Clinic Liver Cancer. 
vs $18.1 \%$, and $61.5 \%$ vs $36.4 \%$ for stages 0 and A, stage B, and stages $\mathrm{C}$ and $\mathrm{D}$, respectively, Table 4).

\section{Survival rates}

The overall survival rates of the 2,045 patients after 1, 3, and 5 years were $44 \%, 25 \%$, and $22 \%$, respectively. The overall survival rates in patients initially hospitalized to surgical divisions were higher than those initially hospitalized into internal medicine divisions (49\% vs 35\%, 27\% vs $21 \%$, and $24 \%$ vs $18 \%$ at 1,3 , and 5 years, respectively, $P<0.001$, Figure 1A).

No significant differences were observed in the pooled survival rates between the surgical and internal medicine divisions after adjusting for treatments $(P=0.364)$.

Stratified analyses were further conducted according to BCLC stages between the surgical and internal medicine divisions. The survival rates of patients with BCLC stages 0 , A, and B initially admitted to surgical divisions were higher than those admitted to internal medicine divisions, with stages $0(P=0.036$, Figure $1 \mathrm{~B})$ and $\mathrm{B}(P<0.001$, Figure $1 \mathrm{D})$ being significantly different, and stage A marginally different ( $P=0.057$, Figure 1C). Survival rates of patients with BCLC stages $\mathrm{C}$ and $\mathrm{D}$ showed no significant differences between surgical and internal medicine divisions $(P=0.268$ and 0.712 , respectively, Figure $1 \mathrm{E}$ and $\mathrm{F}$ ). After adjusting the differences of treatment distribution which might lead to bias, the survival rates showed no significant difference between the patients according to BCLC stages, when initially hospitalized to either surgical or internal medicine divisions ( $P=0.933,0.127$, and 0.917 for stages 0 and $\mathrm{A}$, stage $\mathrm{B}$, and stages $\mathrm{C}$ and $\mathrm{D}$, respectively).

After adjusting the study characteristics in the patients between internal medicine divisions and surgical divisions (Table 1), the initial admissions to internal medicine divisions were not significant risk factors for patients with BCLC stages 0 (relative risk $[R R]=2.019,95 \%$ confidence interval [CI]: 0.411-9.925), A ( $R R=1.329,95 \% \mathrm{CI}: 0.940-1.880)$, $\mathrm{C}(\mathrm{RR}=1.466,95 \% \mathrm{CI}: 0.985-2.182)$, and $\mathrm{D}(\mathrm{RR}=0.945$, 95\% CI: 0.585-1.526), except for those with BCLC stage B $(\mathrm{RR}=1.354,95 \% \mathrm{CI}: 1.154-1.588)$ by the Cox analysis.

\section{Discussion}

This large retrospective study investigated the possible differences in clinical characteristics and survival rates between HCC patients initially admitted to internal medicine and surgical clinical divisions. The findings showed that the clinical characteristics of disease, the treatment options, and the overall survival of patients differed significantly following admission to the two divisions.
Compared with patients initially hospitalized in surgical divisions, patients initially hospitalized to internal medicine divisions had less cryptogenic etiology, higher levels of ALT and AST, and more severe Child-Pugh class and BCLC stages. Although the exact reasons for this phenomenon may be multifactorial, it is understandable that patients with more severe underlying liver diseases are more prone to be referred to physicians associated with internal medicine specialties and to be admitted to divisions of internal medicine because most of their disease conditions may mainly require nonsurgical management.

Higher proportions of patients with different BCLC stages who were initially admitted to internal medicine divisions chose supportive care. In contrast, higher proportions of patients with different BCLC stages who were initially admitted to surgical divisions chose curative therapies. It is understandable that these differences of treatment options would be related to the disease stages of the patients hospitalized and so contribute to the survival differences. However, the treatments of patients with the same HCC stages were significantly variable, and the survival rates were dissimilar, except stages $\mathrm{C}$ and $\mathrm{D}$, when they were initially admitted to internal medicine compared with surgical divisions. Importantly, both the pooled survival rates and the survival rates according to HCC stages vanished after adjusting for treatments when patients initially admitted to internal medicine divisions were compared with admissions to surgical divisions. This indicated that the differences of survival rates are caused by the deviations of treatment options.

The patients with BCLC stages 0 and A were more likely to be initially hospitalized in surgical divisions. It is also understandable that most of the patients with these stages of HCC received surgical management. This is comparable with another study, demonstrating that more patients at early stages saw a surgeon. ${ }^{10}$ However, there were also some inappropriate managements of $\mathrm{HCC}$ in both the internal medicine and surgical divisions. A proportion of patients at BCLC stages 0 and A did not receive potentially curative therapy, especially those who were initially hospitalized to the divisions of internal medicine nature. Inappropriate application of supportive care, instead of curative treatment, may have led to the poorer survival of the patients initially hospitalized to the internal medicine divisions. An Italian study with patients diagnosed with HCC between 2002 and 2008, which appeared to provide no substage information for treatment, showed that $10.9 \%$ of the patients received resection and $29.8 \%$ received percutaneous ablation. ${ }^{5}$ In another study from Taiwan, more than $30 \%$ of the patients with BCLC stages 0 and $A$ received potential curative therapy. ${ }^{7}$ In line 
A

A Overall survival rates between different divisions

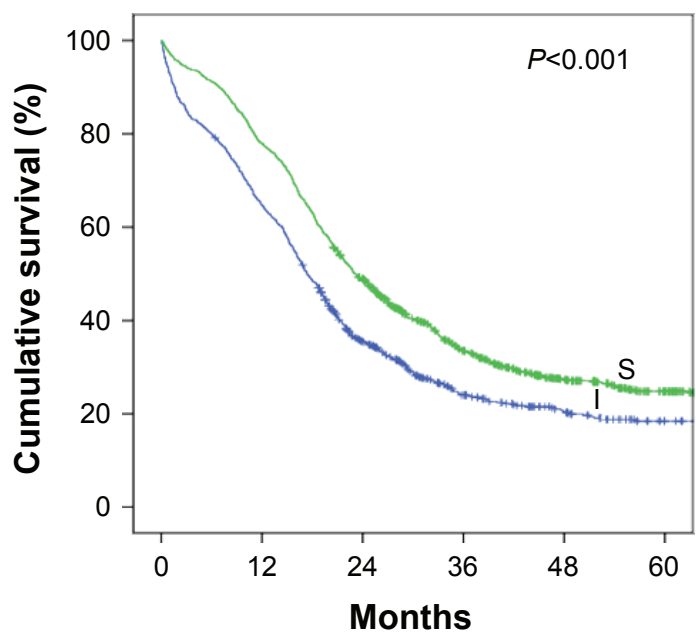

C

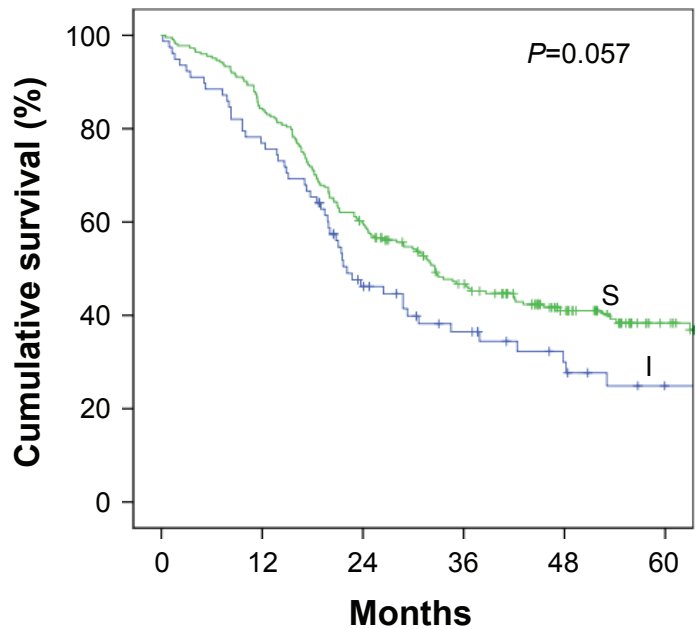

E

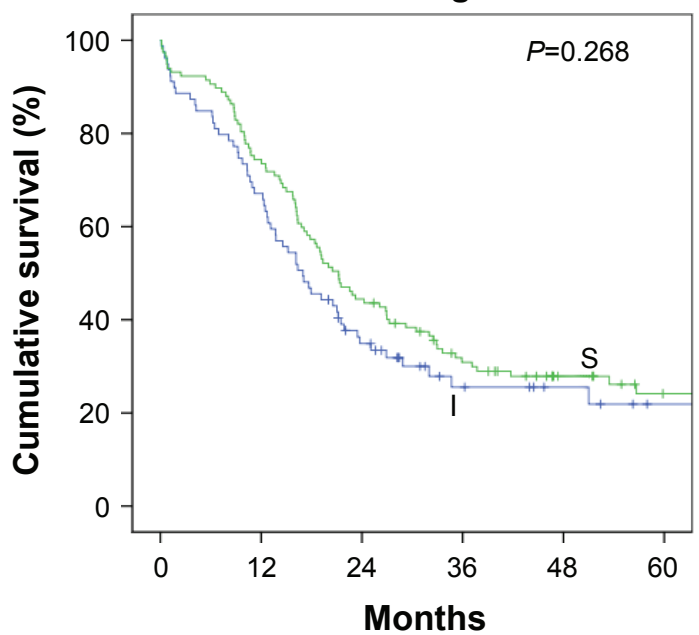

B

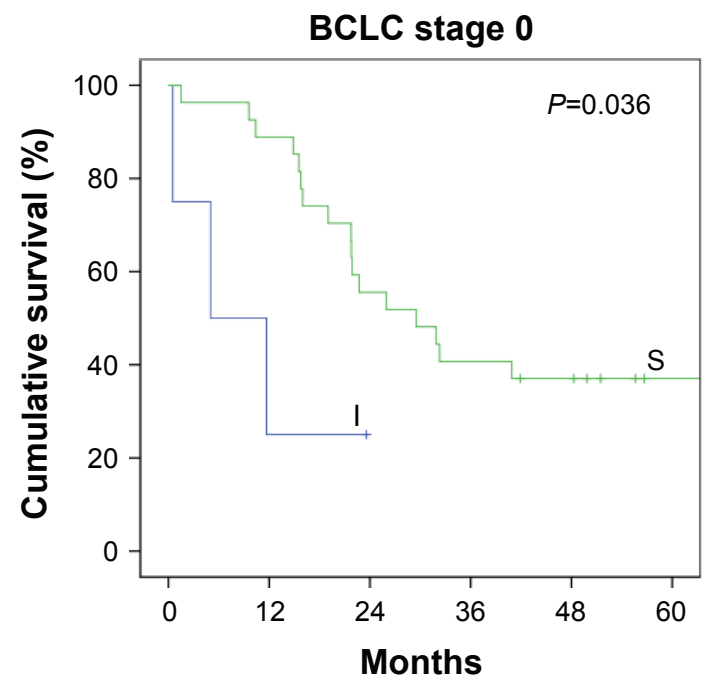

D BCLC stage B

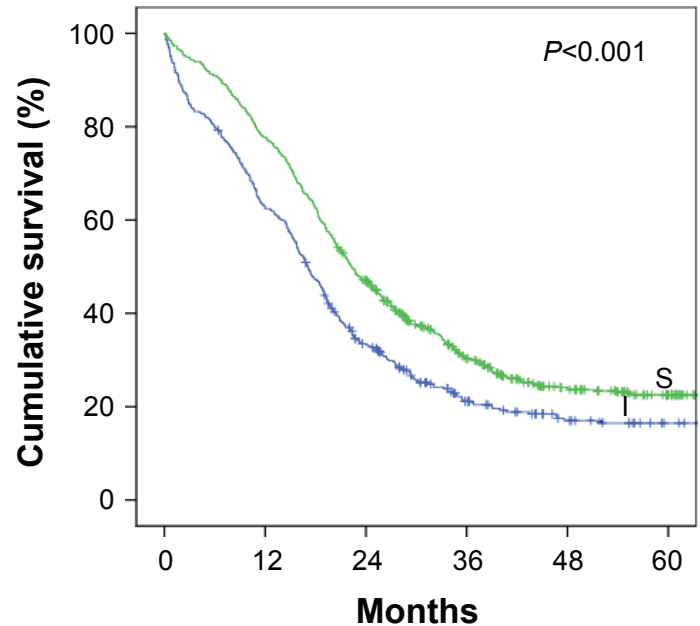

$\mathbf{F}$

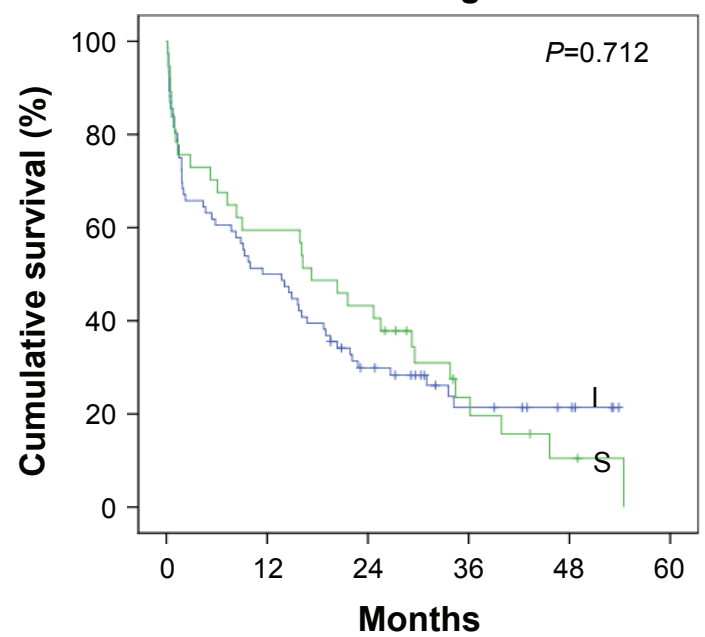

Figure I Survival of hepatocellular carcinoma patients between those initially hospitalized in internal medicine divisions and surgical divisions.

Notes: (A) Overall survival between those initially hospitalized in internal medicine divisions and surgical divisions. (B) Survival of patients at BCLC stage 0 between those initially hospitalized in internal medicine divisions and surgical divisions. (C) Survival of patients at BCLC stage A between those initially hospitalized in internal medicine divisions and surgical divisions. (D) Survival of patients at BCLC stage B between those initially hospitalized in internal medicine divisions and surgical divisions. (E) Survival of patients at BCLC stage $C$ between those initially hospitalized in internal medicine divisions and surgical divisions. (F) Survival of patients at BCLC stage $D$ between those initially hospitalized in internal medicine divisions and surgical divisions.

Abbreviations: BCLC, Barcelona Clinic Liver Cancer; I, internal medicine divisions; S, surgical divisions. 
with these studies, ${ }^{5,7}$ more than $40 \%$ of patients at stages 0 and $\mathrm{A}$ initially hospitalized to the surgical divisions in our study received resection or percutaneous ablation. However, for the HCC patients with BCLC stages 0 and A initially hospitalized to internal medicine divisions, only $3.7 \%$ and $11.0 \%$ of them received resection and percutaneous ablation. The underutilization of therapy for early-stage HCC also existed in another region. ${ }^{18}$ There may be some interpretations which might partially account for the apparent unfavorable application of HCC therapy. The study in the USA found that patients were more likely to receive surgery after consulting a surgeon, ${ }^{10}$ and institution-related factors may also impact the therapy choice for early HCC. ${ }^{9}$ It is, therefore, suggested that the physicians associated with internal medicine specialties may tend to recommend and apply non-surgical therapy for the patients even at early stages of $\mathrm{HCC}$, resulting in underutilization of curative therapies and the subsequent decreased survival.

For patients with BCLC stage B, a higher proportion of patients initially admitted to the surgical divisions received potentially curative therapies $(42.3 \%)$, and the proportion of those initially admitted to the internal medicine divisions receiving these therapies was much lower (7.2\%) - although the patients with BCLC stage B initially admitted to internal medicine and surgical divisions were similar in percentage (62.9\% vs $64.0 \%, P=0.628)$. The survival of patients initially admitted to surgical divisions was significantly higher than that of patients admitted to internal medicine divisions. These results suggest that the increased utilization of curative therapies for BCLC stage B HCC patients results in increased overall survival. It should be mentioned that the initial admission to internal medicine divisions was a risk factor for survival of patients with BCLC stage B in Cox analysis. This might be attributed to the complexity of patients with BCLC stage $\mathrm{B}$ in that patients with BCLC stage B were involved in more treatment choices than those with other stages. The inner relation of the characteristics, such as the ALT and AST and Child-Pugh class, might also lead to the bias of Cox analysis. Therefore, the potential effects of clinical divisions where the patients are admitted and managed on HCC patient survival might need to be explored in multicenter studies.

For patients with HCC stages C and D, a higher proportion of patients initially admitted to surgical divisions also utilized potentially curative therapies $(26.0 \%)$ than those initially admitted to internal medicine divisions (5.8\%). However, the survival of patients in the two groups was not significantly different. These data suggest that the increased application of potentially curative therapy in patients initially admitted to the surgical divisions results in no significant survival benefit for the patients at these stages of disease. A population-based study from the USA also showed that $19.2 \%$ of patients with unfavorable tumor features received potentially curative therapy. ${ }^{18}$

Several possible reasons could explain the differences in the management options between the internal medicine and surgical divisions. The complexity of HCC, including the etiology, co-morbidity, or underlying associated liver disease, may affect the treatment choice. The patient's economic condition is likely another important determinant of treatment, ${ }^{19,20}$ which may be particularly relevant to our study which was conducted in patients from northwest China, a relatively undeveloped area. Besides these factors, the impact of doctors' specialty on the therapy choices should not be ignored. ${ }^{21}$ Internal medicine physicians might focus more on the etiology, liver function, and the underlying liver diseases, while surgeons might pay more attention to the local tumor lesion per se and the option of curative treatments. Insufficient interactive referral and consultation between physicians from divisions to which patients were initially hospitalized and those from other related divisions may also be partially responsible. An insufficient level of surgical referrals by oncologists and gastroenterologists has previously been reported for cases of pancreatic cancer. ${ }^{22}$

Therefore, cooperation is important between divisions of different disciplines for treating HCC. The MDT has been demonstrated to be effective cancer management treatment ${ }^{23}$ and to significantly benefit patients with advanced HCC. ${ }^{24}$ Specialists in infectious diseases, hepatology, gastroenterology, oncology, hepatobiliary surgery, and general surgery are typically involved in the management of HCC patients. Internal medicine specialists including specialists in infectious diseases, hepatology, gastroenterology, and oncology represent the first contact with patients for treating the underlying liver disease including antiviral therapy, which may delay HCC development. ${ }^{25}$ These internal medicine specialists would also play an important role in recommending lifestyle changes and arranging surveillance. ${ }^{11,26}$ After diagnosis, the surgeon and interventional therapist would play their role in evaluating the possibility of resection, transplantation, percutaneous local ablation, or TACE, and the internal medicine physicians monitor the liver function and alleviating symptoms of the patients. ${ }^{11,26}$ Meanwhile, other specialists such as specialists in tomography and pathology and nurses would also be involved in diagnosing and/or treating $\mathrm{HCC} .{ }^{26}$ It has been demonstrated that, although some practical barriers would weaken the effectiveness, ${ }^{13}$ multidisciplinary collaboration could improve the survival of $\mathrm{HCC}$ patients. ${ }^{24}$ 
Several potential limitations of our present study should be noticed. First, the present study was retrospective and this might affect the reliability of the study. Second, the results of present single-center study from northwest China where the work of MDT is in its initial and preliminary stage might not be applicable to the other clinical centers where the MDT work is mature. Third, some other clinical factors such as antiviral therapy which could not be extracted in the present retrospective study were not included in Cox analysis and this might lead to bias. However, Kaplan-Meier method and subgroup analysis were also used in the present study to verify the results from different analyses and minimize the potential influence of these limitations.

In conclusion, the results of our study, for the first time to our knowledge, demonstrate the existence of inappropriate utilization of treatments between HCC patients initially hospitalized in divisions of internal and surgical medicine and how this affects patient survival using data from a large medical center in northwest China over a 10 -year period. The underutilization of curative treatments in patients at stages 0 , A, and B initially admitted to internal medicine divisions is associated with decreased survival for patients, whereas the overutilization of curative treatments in patients with stages $\mathrm{C}$ and D initially admitted to surgical divisions brings no improvement for the survival of the patients. The analysis of our study also provides insight into the possible reasons for the inappropriate utilization of treatments between HCC patients initially hospitalized in internal medicine versus surgical divisions and emphasizes the importance of sufficient multidisciplinary collaboration, which has been shown to be associated with change of therapy choice and survival in patients with HCC or other cancers..$^{24,27}$ Therefore, enforcing multidisciplinary collaboration to optimize the treatment of HCC patients at various disease stages is an imperative issue for clinical practice likely to improve patient survival. However, in view of the retrospective nature of this study in a single center which may lack many other factors associated with the choice of HCC therapy, such as the economic condition or unmeasured comorbid illness, caution should, therefore, be warranted in the interpretation and generalization of these findings, and further prospective studies in multiple centers with more factors are needed to extend our findings.

\section{Acknowledgment}

This study was supported by the National Natural Science Foundation of China (Grant no 81371798). We thank Professor David J Pintel from the Department of Molecular
Microbiology and Immunology, School of Medicine, University of Missouri-Columbia, Columbia, Missouri, for his thorough editing of this manuscript. We thank Doctor Rong Peng and all the other staff of the Division of Medical Record Information of the hospital for their help in the data collection of this study.

\section{Disclosure}

The authors report no conflicts of interest in this work.

\section{References}

1. Ferenci P, Fried M, Labrecque D, et al; World Gastroenterology Organization. Hepatocellular carcinoma (HCC): a global perspective. J Clin Gastroenterol. 2010;44(4):239-245.

2. El-Serag HB. Hepatocellular carcinoma. N Engl J Med. 2011;365(12): 1118-1127.

3. Forner A, Llovet JM, Bruix J. Hepatocellular carcinoma. Lancet. 2012;379(9822):1245-1255.

4. Llovet JM, Burroughs A, Bruix J. Hepatocellular carcinoma. Lancet. 2003;362(9399):1907-1917.

5. Santi V, Buccione D, Di Micoli A, et al. The changing scenario of hepatocellular carcinoma over the last two decades in Italy. J Hepatol. 2012;56(2):397-405

6. Bruix J, Sherman M. Management of hepatocellular carcinoma: an update. Hepatology. 2011;53(3):1020-1022.

7. Wang JH, Changchien CS, Hu TH, et al. The efficacy of treatment schedules according to Barcelona clinic liver cancer staging for hepatocellular carcinoma - Survival analysis of 3892 patients. Eur J Cancer. 2008;44(7):1000-1006.

8. Lencioni R, Chen XP, Dagher L, et al. Treatment of intermediate/ advanced hepatocellular carcinoma in the clinic: how can outcomes be improved? Oncologist. 2010;15(Suppl 4):42-52.

9. Nathan H, Segev DL, Bridges JF, et al. Influence of nonclinical factors on choice of therapy for early hepatocellular carcinoma. Ann Surg Oncol. 2013;20(2):448-456.

10. Hyder O, Dodson RM, Nathan H, et al. Referral patterns and treatment choices for patients with hepatocellular carcinoma: a United States population-based study. J Am Coll Surg. 2013;217(5):896-906.

11. Barone C, Koeberle D, Metselaar H, et al. Multidisciplinary approach for HCC patients: hepatology for the oncologists. Ann Oncol. 2013; 24(Suppl 2):ii15-ii23.

12. Saini KS, Taylor C, Ramirez AJ, et al. Role of the multidisciplinary team in breast cancer management: results from a large international survey involving 39 countries. Ann Oncol. 2012;23(4):853-859.

13. Fleissig A, Jenkins V, Catt S, Fallowfield L. Multidisciplinary teams in cancer care: are they effective in the UK? Lancet Oncol. 2006;7(11): 935-943.

14. Hong NJ, Wright FC, Gagliardi AR, Paszat LF. Examining the potential relationship between multidisciplinary cancer care and patient survival: an international literature review. J Surg Oncol. 2010;102(2): 125-134.

15. Taylor C, Shewbridge A, Harris J, Green JS. Benefits of multidisciplinary teamwork in the management of breast cancer. Breast Cancer (Dove Med Press). 2013;5:79-85.

16. Zhu Q, Li N, Zeng X, et al. Hepatocellular carcinoma in a large medical center of China over a 10-year period: evolving therapeutic option and improving survival. Oncotarget. 2015;6(6):4440-4450.

17. Marrero JA, Fontana RJ, Barrat A, et al. Prognosis of hepatocellular carcinoma: comparison of 7 staging systems in an American cohort. Hepatology. 2005;41(4):707-716.

18. El-Serag HB, Siegel AB, Davila JA, et al. Treatment and outcomes of treating of hepatocellular carcinoma among Medicare recipients in the United States: a population-based study. J Hepatol. 2006;44(1): $158-166$. 
19. Jembere N, Campitelli MA, Sherman M, et al. Influence of socioeconomic status on survival of hepatocellular carcinoma in the Ontario population; a population-based study, 1990-2009. PLoS One. 2012; 7(7):e40917.

20. Wong LL, Hernandez BY, Albright CL. Socioeconomic factors affect disparities in access to liver transplant for hepatocellular cancer. J Transplant. 2012;2012:870659.

21. Nathan H, Bridges JF, Schulick RD, et al. Understanding surgical decision making in early hepatocellular carcinoma. J Clin Oncol. 2011; 29(6):619-625.

22. Riall TS, Lillemoe KD. Underutilization of surgical resection in patients with localized pancreatic cancer. Ann Surg. 2007;246(2):181-182.

23. Taylor C, Munro AJ, Glynne-Jones R, et al. Multidisciplinary team working in cancer: what is the evidence? BMJ. 2010;340:c951.

24. Chang TT, Sawhney R, Monto A, et al. Implementation of a multidisciplinary treatment team for hepatocellular cancer at a Veterans Affairs Medical Center improves survival. HPB (Oxford). 2008;10(6): 405-411.
25. Shen YC, Hsu C, Cheng CC, Hu FC, Cheng AL. A critical evaluation of the preventive effect of antiviral therapy on the development of hepatocellular carcinoma in patients with chronic hepatitis $\mathrm{C}$ or $\mathrm{B}$ : a novel approach by using meta-regression. Oncology. 2012;82(5):275-289.

26. Gish RG, Lencioni R, Di Bisceglie AM, Raoul JL, Mazzaferro V. Role of the multidisciplinary team in the diagnosis and treatment of hepatocellular carcinoma. Expert Rev Gastroenterol Hepatol. 2012; 6(2):173-185.

27. Prades J, Remue E, van Hoof E, Borras JM. Is it worth reorganising cancer services on the basis of multidisciplinary teams (MDTs)? A systematic review of the objectives and organisation of MDTs and their impact on patient outcomes. Health Policy. 2015;119(4):464-474.

\section{Publish your work in this journal}

Therapeutics and Clinical Risk Management is an international, peerreviewed journal of clinical therapeutics and risk management, focusing on concise rapid reporting of clinical studies in all therapeutic areas, outcomes, safety, and programs for the effective, safe, and sustained use of medicines. This journal is indexed on PubMed Central, CAS,
EMBase, Scopus and the Elsevier Bibliographic databases. The manuscript management system is completely online and includes a very quick and fair peer-review system, which is all easy to use. Visit http://www.dovepress.com/testimonials.php to read real quotes from published authors.

Submit your manuscript here: http://www.dovepress.com/therapeutics-and-clinical-risk-management-journal 